\title{
OTIMIZAÇÃO DA PRODUÇÃO DO CARVÃO VEGETAL POR MEIO DO CONTROLE DE TEMPERATURAS DE CARBONIZAÇÃO ${ }^{1}$
}

\author{
Aylson Costa Oliveira ${ }^{2}$, Angélica de Cássia Oliveira Carneiro ${ }^{3}$, Bárbara Luísa Corradi Pereira ${ }^{2}$, Benedito \\ Rocha Vital ${ }^{3}$, Ana Márcia Macedo Ladeira Carvalho ${ }^{3}$, Paulo Fernando Trugilho ${ }^{4}$ e Renato Augusto
}

Pereira Damásio ${ }^{5}$

\begin{abstract}
RESUMO - Embora nos últimos anos diversas pesquisas tenham sido desenvolvidas com o intuito de melhorar os índices de qualidade da madeira (densidade básica, composição química), grande parte da produção brasileira de carvão ainda ocorre em fornos com baixo rendimento gravimétrico e com emissões de gases poluentes. Na tentativa de alterar esse cenário, este trabalho objetivou avaliar o funcionamento de um sistema fornofornalha e também o ajuste de faixas de controle da carbonização em função do tempo e da temperatura, levando-se em consideração a degradação térmica da madeira, com vistas a maximizar o rendimento em carvão vegetal. Foram construídos três fornos circulares de alvenaria acoplados a uma fornalha, para queima dos gases gerados durante a carbonização. O controle da carbonização foi realizado através da mensuração da temperatura interna com sensor infravermelho. De acordo com os resultados, o controle da carbonização realizado com base nas faixas de carbonização proporcionou rendimento médio de 33\% de carvão, $8 \%$ de atiço e 3\% de finos. A fornalha mostrou-se eficiente na redução de emissão de fumaça para o ambiente, funcionando durante um terço do tempo de carbonização. Conclui-se que o sistema forno-fornalha apresenta produção satisfatória de carvão vegetal, com baixa emissão de fumaça durante a carbonização da madeira.
\end{abstract}

Palavras-chave: Carbonização de madeira; Fornalha; Forno de superfície; Baixa emissão de fumaça.

\section{OPTIMIZATION OF CHARCOAL PRODUCTION THROUGH CONTROL OF CARBONIZATION TEMPERATURES}

\begin{abstract}
Although in recent years several studies have been done with the aim of improving the wood quality indices (basic density, chemical composition), much of the Brazilian charcoal production still occurs in kilns that have low gravimetric yield and uncontrolled emissions of polluting gases. In an attempt to change this scenario, this work was developed with the objective of evaluating the operation of a kiln-furnace system. The work also aimed to adjust carbonization control ranges according to temperature and time, taking into account the thermal degradation of wood in order to maximize the yield of charcoal. Three kilns were built, attached to a furnace for burning the gases generated during the carbonization. Control of carbonization was conducted using internal temperature, measured by an infrared temperature sensor. According to the results, controlling time and temperature during the carbonization provided average gravimetric yields of $33 \%$ charcoal, $8 \%$ semi-carbonized wood and 3\% fines (particle size less than $12.7 \mathrm{~mm}$ ). The furnace was efficient in reducing fume to the environment, working for a third time carbonization. It is concluded that the kiln-furnace system presents satisfactory production of charcoal, with low fume during carbonization.
\end{abstract}

Keywords: Wood carbonization; Furnace; Surface kiln; Low emission of fume.

\footnotetext{
${ }^{1}$ Recebido em 23.08.2012 aceito para publicação em 24.05.2013.

${ }^{2}$ Programa de Pós-Graduação em Ciência Florestal pela Universidade Federal de Viçosa, UFV, Brasil. E-mail: <aylsoncosta@gmail.com>e < babicorradi@gmail.com>.

${ }^{3}$ Departamento de Engenharia Florestal da Universidade Federal de Viçosa, UFV, Brasil. E-mail: <cassiacarneiro1@ gmail.com>, <bvital@ufv.br>e<ana.marcia@ufv.br>.

${ }^{4}$ Departamento de Ciências Florestais da Universidade Federal de Lavras, UFLA, Brasil. E-mail: <trugilho@ dcf.ufla.br>.

${ }^{5}$ Graduação em Engenharia Florestal pela Universidade Federal de Viçosa, UFV, Brasil. E-mail: <damasio.renato@ gmail.com>.
} 


\section{INTRODUÇÃO}

No Brasil, o carvão vegetal destina-se quase que exclusivamente ao setor siderúrgico, em que exerce a função de termorredutor do minério de ferro para a produção de ferro-gusa, aço e ferro-liga (ABRAF, 2012). Nas últimas décadas, a cadeia produtiva de carvão vegetal tem buscado a modernização e melhoria da tecnologia empregada na conversão da madeira em carvão, além de substituir a matéria-prima oriunda da mata nativa por madeira do gênero Eucalyptus obtida através das florestas plantadas, alcançando, assim, maior qualidade e homogeneidade do produto (REZENDE; SANTOS, 2010).

Ainda assim, a produção brasileira de carvão vegetal continua ocorrendo em fornos rudimentares de alvenaria. Os pequenos e médios produtores, responsáveis por cerca de $80 \%$ da produção total de carvão, optam pelos fornos de baixa capacidade volumétrica, devido ao elevado custo com maquinário e ao maior investimento inicial para a construção de fornos de maiores dimensões. Segundo Carvalho et al. (2012), esses produtores utilizam fornos de diferentes formatos para produção de carvão vegetal, destacando-se os fornos do tipo "rabo-quente", superfície e encosta. Porém, esses fornos apresentam baixo rendimento gravimétrico e emissões não controladas de gases poluentes para o ambiente.

A alternativa para aproveitamento dos gases gerados durante a carbonização seria através da condensação, em que se obtêm o alcatrão e o licor pirolenhoso. Contudo, não existe cadeia sólida e sustentável, abrangendo a produção, coprocessamento e consumo desses subprodutos, desestimulando sua recuperação. Atualmente, a alternativa mais interessante tem sido a combustão dos gases em fornalhas que proporciona, ao mesmo tempo, a melhoria do ambiente de trabalho e a obtenção de energia térmica (CARDOSO et al., 2010). Essa energia gerada pode ser empregada na secagem da lenha a ser carbonizada ou, mesmo, para a produção de energia elétrica.

O objetivo deste trabalho foi avaliar o funcionamento de um sistema forno-fornalha com baixa emissão de gases poluentes. Objetivou-se, também, ajustar faixas de controle da carbonização em função do tempo e da temperatura, levando em consideração os aspectos teóricos da degradação térmica dos principais componentes químicos da madeira, visando maximizar o rendimento em carvão vegetal.

\section{MATERIAL E MÉTODOS}

\subsection{Local}

O trabalho foi realizado nas instalações do Laboratório de Painéis e Energia da Madeira - LAPEM, do Departamento de Engenharia Florestal da Universidade Federal de Viçosa - UFV, situada na cidade de Viçosa, Minas Gerais.

\subsection{Descrição do sistema forno-fornalha}

O sistema avaliado consiste em três fornos circulares de superfície (Figura 1), conectados através de ductos a uma fornalha central, ambos construídos com tijolos maciços cerâmicos. Cada forno possui diâmetro interno de $3 \mathrm{~m}$ e altura central de $2,2 \mathrm{~m}$, com capacidade de enfornamento de 12 estéreos (st) de madeira. Na base dos fornos foram deixadas seis aberturas para entrada de ar e, consequentemente, para controle da carbonização.

A fornalha adaptada ao forno é de formato cilíndrico, com diâmetro interno de $1,6 \mathrm{~m}$ e altura de $1,1 \mathrm{~m}$, sendo composta por um sistema de alimentação dos gases, câmara de combustão, sistema de admissão de ar primário e chaminé (Figura 1). Nessa configuração de sistema, a chaminé foi construída sobre a fornalha, com diâmetro interno inferior de $1,6 \mathrm{~m}$, superior de $0,40 \mathrm{~m}$ e altura de $2,9 \mathrm{~m}$.

A parte externa dos fornos, dos ductos, da fornalha e da chaminé foi revestida com uma camada de argamassa de areia lavada, cimento, argamassa refratária, cal virgem e água, com o objetivo de reduzir possíveis entradas de ar e perdas térmicas e também aumentar a durabilidade de todo o sistema.

\subsection{Avaliação do sistema forno-fornalha}

Foram realizadas quatro carbonizações para avaliar o funcionamento e o desempenho do sistema fornofornalha. Utilizou-se madeira com casca de Eucalyptus spp. com 7 anos de idade, diâmetro variando de 10 a $30 \mathrm{~cm}$, altura de 1,50 a 2,20 m e umidade média (base seca) de $42,50 \%$, proveniente de plantio comercial com espaçamento $3 \times 3$, localizado na cidade de Viçosa, MG. A madeira ficou empilhada no campo 90-120 dias, para secagem.

Para o cálculo da umidade média da madeira, em cada carbonização realizada seis toras de madeira representativas da variação de diâmetro foram selecionadas para retirada de discos nas extremidades 
e na porção central da tora. Esses discos foram levados para estufa com circulação forçada de ar, a $103 \pm 2{ }^{\circ} \mathrm{C}$, onde permaneceram até atingir massa constante.

Para monitoramento da temperatura interna do forno durante a carbonização e o resfriamento, foram instalados oito cilindros metálicos, quatro na cúpula (Figura 1) e outros quatro nas paredes laterais do forno avaliado, para medição da temperatura. Um medidor infravermelho de temperatura modelo TD 980, marca ICEL, apropriado para temperaturas de $-50^{\circ} \mathrm{C}$ a $1.050^{\circ} \mathrm{C}$, foi utilizado para monitoramento e registro das temperaturas do forno.

O medidor infravermelho era inserido na extremidade aberta do cilindro, sendo medida a temperatura da outra extremidade do cilindro, sendo esta fechada, que, por estar em contato com o interior do forno, apresenta temperatura semelhante à verificada no forno durante a carbonização ou resfriamento.

De acordo com as temperaturas obtidas, principalmente na parte superior do forno, procederam-se ao fechamento ou à abertura das entradas de ar e, consequentemente, ao controle da carbonização em função das faixas de degradação térmica da madeira, tendo como meta a temperatura máxima final de carbonização média de $470^{\circ} \mathrm{C}$.

A temperatura foi registrada em intervalos de 30 em 30 min, durante todo o processo de carbonização e em intervalo de $8 \mathrm{em} 8 \mathrm{~h}$, para a etapa de resfriamento. A partir das temperaturas médias obtidas dos quatro pontos de medição da cúpula e dos quatro pontos instalados nas paredes do forno, procedeu-se à confecção do perfil térmico de cada carbonização.

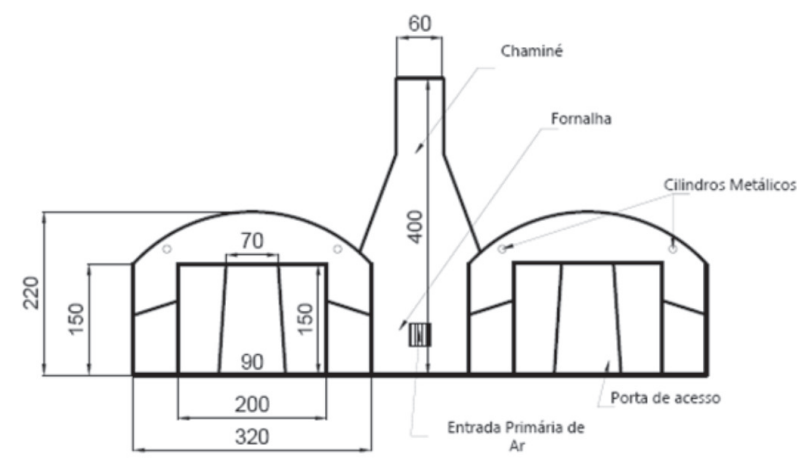

Figura 1 - Vista frontal do sistema forno-fornalha, com medidas em cm. Escala 1:20.

Figure 1 - Front view of kiln-furnace system, with measures in cm. Scale: $1: 20$.
Simultaneamente à ignição do forno, realizou-se o acendimento da fornalha, que foi abastecida com resíduos lignocelulósicos, como madeira semicarbonizada, galhos, madeira apodrecida, casca. Abastecimentos posteriores foram necessários para manter a chama acessa e elevar a temperatura na fornalha, até que os gases gerados durante a carbonização fossem capazes de manter a combustão em seu interior. A eficiência da fornalha foi determinada através da relação do tempo total de queima sem a necessidade de abastecimentos com resíduos com o tempo total de carbonização.

Após o resfriamento do forno, procedeu-se à sua abertura, realizando a descarga e pesagem do carvão, dos finos (carvão com granulometria inferior a 12,7 mm) e atiços (madeira parcialmente carbonizada).

O rendimento gravimétrico de cada carbonização foi determinado através da divisão das massas dos produtos obtidos pela massa seca de madeira enfornada.

\section{RESULTADOS}

\subsection{Faixas teóricas de carbonização}

$\mathrm{Na}$ produção de carvão vegetal em fornos conectados a uma fornalha não é possível o controle da carbonização pela coloração dos gases devido à sua combustão, liberando $\mathrm{CO}_{2}$, calor e vapor de água. Logo, foi necessário obter as temperaturas e respectivos tempos para a carbonização da madeira, de modo a obter maior rendimento gravimétrico em carvão.

Na Tabela 1 são apresentadas as faixas teóricas de temperatura obtidas para o controle da carbonização da madeira nesse sistema forno-fornalha. Essas faixas foram obtidas após a realização de carbonizações preliminares sem o controle adequado da temperatura que apresentaram baixo rendimento em carvão vegetal devido à má condução da carbonização; no tempo ideal de 70 h para carbonização em forno de superfície; na constituição química da madeira de eucalipto (PEREIRA, 2012); e na degradação térmica dos seus principais componentes (RAAD et al., 2006; SANTOS et al., 2012).

As faixas de temperatura foram determinadas considerando-se, principalmente, a temperatura mensurada na parte superior do forno, visto que a temperatura média da parte inferior deste esteve abaixo desses valores.

Revista Árvore, Viçosa-MG, v.37, n.3, p.557-566, 2013 
Tabela 1 - Faixas teóricas de temperatura para controle da carbonização no sistema forno-fornalha, a serem mensuradas na cúpula do forno.

Table 1 - Theoretical tracks temperature for carbonization control in kiln-furnace system, to be measured at dome of kiln.

\begin{tabular}{|c|c|c|c|}
\hline Fase & $\begin{array}{l}\text { Faixa de } \\
\text { temperatura }\left({ }^{\circ} \mathrm{C}\right)\end{array}$ & $\begin{array}{l}\text { Tempo de } \\
\text { manutenção (horas) }\end{array}$ & Fenômeno \\
\hline I & $100-150$ & $15-16$ & Liberação de vapor de água - secagem da madeira, fase endotérmica \\
\hline II & $150-275$ & $11-12$ & Degradação das hemiceluloses, eliminação de gases, fase endotérmica \\
\hline III & $275-400$ & $23-24$ & $\begin{array}{l}\text { Degradação da celulose, grande produção de gases, fase exotérmica. } \\
\text { Formação do carvão vegetal }\end{array}$ \\
\hline IV & $400-470$ & $17-18$ & $\begin{array}{l}\text { Redução da emissão de gases, fase exotérmica. Aumento da } \\
\text { concentração de carbono no carvão vegetal }\end{array}$ \\
\hline
\end{tabular}

\subsection{Perfil térmico do forno}

Arruda et al. (2011) ressaltaram que a determinação da temperatura interna do forno permite a obtenção do perfil térmico da carbonização e do resfriamento condizentes com os fenômenos que realmente ocorrem. Essas informações são utilizadas para o melhor controle dos processos, resultando em maior rendimento gravimétrico da carbonização e melhoria da qualidade do carvão vegetal.

A Figura 2A representa a variação da temperatura média da cúpula do forno observada durante as quatro carbonizações realizadas.

Para garantir rendimento gravimétrico satisfatório de carvão vegetal com baixa geração de atiço e finos, as temperaturas da parte inferior do forno também foram controladas, buscando-se maior proximidade possível das temperaturas observadas na parte superior. A Figura 2B representa a variação da temperatura média da parede do forno observada durante as quatro carbonizações realizadas.

Para as carbonizações realizadas neste trabalho, o término da carbonização ocorreu na $70^{\mathrm{a}}$ hora, momento em que cessou o fluxo de gases do forno para a fornalha e a temperatura do forno diminuiu naturalmente (Figura $2 \mathrm{AB}$ ). Nesse momento, realizou-se o fechamento de todas as entradas de ar, bem como sua vedação com argamassa de solo argiloso, areia e água.

O resfriamento ocorreu de maneira natural, mediante a simples troca de calor do forno com o ambiente, até que a temperatura interna atingisse média inferior a $40{ }^{\circ} \mathrm{C}$, temperatura que assegura a abertura do forno e a descarga do carvão vegetal sem riscos de incêndio.

Revista Árvore, Viçosa-MG, v.37, n.3, p.557-566, 2013
O tempo médio de resfriamento foi de $50 \mathrm{~h}$. Ressalta-se que esse tempo foi devido às baixas temperaturas do ambiente na época de realização das carbonizações, cuja temperatura média foi de $18,0^{\circ} \mathrm{C}$, com mínima de $12,2^{\circ} \mathrm{C}$ e máxima de $27,2^{\circ} \mathrm{C}$.

\subsection{Funcionamento da fornalha}

O principal objetivo do acoplamento de uma fornalha a um sistema de produção de carvão vegetal é realizar a queima dos gases gerados no interior do forno durante a carbonização da madeira, reduzindo, assim, as emissões de gases para a atmosfera e transformando a poluição em calor. Na Tabela 2 estão os valores médios dos parâmetros de funcionamento da fornalha em cada faixa de carbonização proposta para esse sistema fornofornalha.

\subsection{Rendimentos gravimétricos das carbonizações}

Os rendimentos gravimétricos em carvão vegetal, atiço e finos obtidos nas carbonizações realizadas no sistema forno-fornalha estão apresentados na Tabela 3.

\section{DISCUSSÃO}

\subsection{Faixas teóricas de carbonização}

Observa-se, na Tabela 1, que a fase endotérmica teve duração média de 28 h (40\% do tempo total de carbonização), enquanto a fase exotérmica durou 42 h, correspondendo a $60 \%$ do tempo de carbonização no sistema forno-fornalha.

O tempo de manutenção para a etapa de secagem da madeira foi de aproximadamente $16 \mathrm{~h} \mathrm{(23 \%} \mathrm{do}$ tempo total de carbonização) para madeira com umidade média de $42,5 \%$, base seca. Ressalta-se que a umidade da madeira tem grande influência sobre essa etapa, 

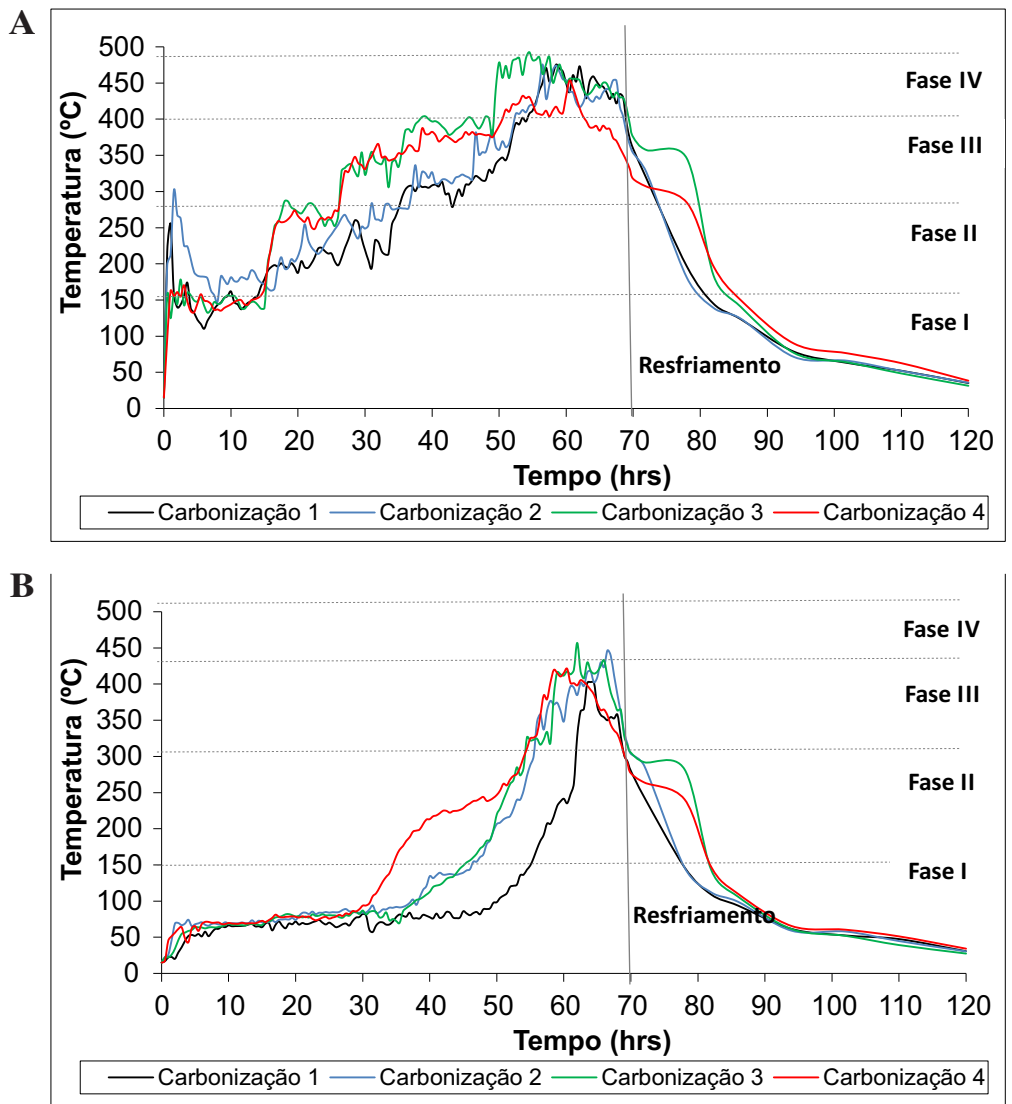

Figura 2 - Temperaturas médias do forno durante as carbonizações. A) cúpula do forno; e B) parede do forno. Figure 2 -Average temperatures of kiln during carbonizations. A) kiln dome; and B) Kiln wall.

Tabela 2 - Valores médios dos parâmetros de funcionamento da fornalha em cada faixa de carbonização. Table 2 -Average values of operating parameters of furnace in each carbonization track.

\begin{tabular}{lcccc}
\hline \multicolumn{1}{c}{ Parâmetro } & \multicolumn{3}{c}{ Faixa de carbonização } \\
\cline { 2 - 5 } & I & II & III & IV \\
\hline Temperatura da cúpula do forno & $145{ }^{\circ} \mathrm{C}$ & $260{ }^{\circ} \mathrm{C}$ & $375{ }^{\circ} \mathrm{C}$ & $430^{\circ} \mathrm{C}$ \\
Temperatura da parede do forno & $60{ }^{\circ} \mathrm{C}$ & $80{ }^{\circ} \mathrm{C}$ & $170{ }^{\circ} \mathrm{C}$ & $345^{\circ} \mathrm{C}$ \\
Temperatura de saída dos gases do forno & $30{ }^{\circ} \mathrm{C}$ & $55{ }^{\circ} \mathrm{C}$ & $160{ }^{\circ} \mathrm{C}$ & $250^{\circ} \mathrm{C}$ \\
Temperatura de saída dos gases na chaminé & $260{ }^{\circ} \mathrm{C}$ & $300{ }^{\circ} \mathrm{C}$ & $400{ }^{\circ} \mathrm{C}$ & $440{ }^{\circ} \mathrm{C}$ \\
Consumo de resíduo (massa seca) & $500 \mathrm{~kg}$ & $300 \mathrm{~kg}$ & $100 \mathrm{~kg}$ & $200 \mathrm{~kg}$ \\
\hline
\end{tabular}

Tabela 3 - Rendimentos gravimétricos do sistema forno-fornalha.

Table 3 - Gravimetric yield of kiln-furnace system.

\begin{tabular}{|c|c|c|c|c|}
\hline \multirow{2}{*}{ Carbonização } & \multicolumn{3}{|c|}{ Rendimento (\%) } & \multirow{2}{*}{ Umidade da madeira (\%) } \\
\hline & Carvão & Atiço & Finos & \\
\hline 1 - Ajuste & 26,40 & 21,60 & 4,10 & 41,25 \\
\hline 2 & 32,15 & 12,42 & 3,14 & 42,67 \\
\hline 3 & 31,80 & 10,83 & 3,54 & 44,86 \\
\hline 4 & 35,61 & 3,28 & 3,02 & 41,28 \\
\hline
\end{tabular}


pois, quanto maior a umidade inicial, maior o tempo necessário para eliminação de toda a água, acarretando, assim, aumento da fase endotérmica do processo. De acordo com Arruda et al. (2011), a fase de secagem da madeira empregada na produção de carvão vegetal ocorre no interior do forno nos intervalos de temperatura de 110 a $200^{\circ} \mathrm{C}$. Nessa etapa, nos sistemas autotérmicos ocorre o consumo de parte da madeira enfornada para evaporação da água, sendo o processo endotérmico.

Havendo a possibilidade de uso de madeira com umidade inferior à utilizada neste estudo, o tempo dessa primeira etapa poderia ser reduzido, fato que acarretaria diminuição do tempo total de carbonização, elevando a produtividade do sistema forno-fornalha.

No intervalo de temperatura entre 150 e $275^{\circ} \mathrm{C}$ ocorrem maior degradação das hemiceluloses e menor degradação da celulose e lignina (YANG et al., 2007). Essa fase apresenta menor tempo de duração, $12 \mathrm{~h}$ ( $17 \%$ do tempo total de carbonização), uma vez que nessa faixa de temperatura ocorrem a degradação das hemiceluloses e polímero menos estável termicamente que os demais e, segundo Sjöström (1993), constituem 20 a 30\% da madeira. Para madeiras de eucalipto visando à produção de carvão vegetal, normalmente o teor médio de hemiceluloses está em torno de 22\% (PEREIRA, 2012). As ramificações presentes nas hemiceluloses são facilmente removidas da cadeia principal e degradam-se em compostos voláteis, como $\mathrm{CO}, \mathrm{CO}_{2}$ e alguns hidrocarbonetos, em baixas temperaturas (YANG et al., 2007). Nessa segunda fase de carbonização, o processo ainda é endotérmico, ou seja, a energia requerida para a quebra das estruturas químicas dos componentes da madeira é maior que a energia liberada.

A celulose constitui cerca de 40 a $50 \%$ da massa seca de madeira e, segundo Yang et al. (2007), sua degradação térmica máxima ocorre na temperatura de $355^{\circ} \mathrm{C}$. Segundo Pereira (2012), madeiras de eucalipto destinadas à produção de carvão vegetal apresentam teor médio de celulose igual a $47 \%$. Portanto, a faixa de temperatura e o tempo de manutenção proposto neste trabalho que compreende a temperatura de degradação da celulose variaram de 275 a $400{ }^{\circ} \mathrm{C}$. Por ser a celulose o constituinte presente em maior massa na madeira, essa fase teve maior duração, em torno de $24 \mathrm{~h}$, correspondendo a $34 \%$ do tempo total de carbonização. Ressalta-se que a partir dessa fase acontecem as principais reações exotérmicas do processo, havendo elevada liberação de $\mathrm{CO}, \mathrm{CO}_{2} \mathrm{e}$ $\mathrm{CH}_{4}$ (TACCINI, 2011).

Na quarta e última fase, a temperatura média variou de 400 a $470{ }^{\circ} \mathrm{C}$ e teve duração média de 18 h $(26 \%$ do tempo de carbonização). Nessas condições, verificou-se a ocorrência da maior degradação térmica da lignina. Segundo Frederico (2009), 50\% do carbono fixo presente no carvão vegetal é devido à degradação da lignina. Nessa fase ocorreu a redução da vazão dos gases em função da diminuição dos compostos voláteis e fixação do carbono fixo no carvão vegetal. Vale ressaltar que a maior temperatura final de carbonização proporciona o aumento do carbono fixo no carvão vegetal com a diminuição do teor de materiais voláteis e redução no rendimento gravimétrico em carvão (OLIVEIRA et al., 2010).

Visando aumentar a produtividade do sistema e não havendo necessidade de carbono fixo acima de $80 \%$, pode-se diminuir o tempo de manutenção da quarta fase de carbonização, assim como reduzir o limite de temperatura de 470 para $450{ }^{\circ} \mathrm{C}$.

\subsection{Perfil térmico do forno}

Em relação às temperaturas obtidas na cúpula do forno (Figura 2A), durante a primeira carbonização o forno permaneceu $35 \mathrm{~h}$ exposto a temperaturas inferiores a $275^{\circ} \mathrm{C}$, quando o desejado seria $28 \mathrm{~h}$, conforme estabelecido na Tabela 1 . Na faixa de temperatura variável de 275 a $400{ }^{\circ} \mathrm{C}$ (terceira fase), o tempo de exposição foi de $19 \mathrm{~h}$, tempo inferior ao necessário para que ocorressem as reações suficientes para a carbonização da madeira. Na última fase da carbonização, cuja temperatura máxima deve ser inferior ou igual a $470^{\circ} \mathrm{C}$, o tempo total de exposição foi de $16 \mathrm{~h}$. Para essa carbonização, a temperatura máxima $\left(476^{\circ} \mathrm{C}\right)$ medida na cúpula do forno ocorreu na $59^{\text {a }}$ hora.

Para a segunda carbonização foram abertos dois novos controladores de ar próximo à porta para aumentar a entrada de oxigênio no interior do forno e, assim, haver maior incremento da temperatura do forno durante a carbonização da madeira. Dessa forma, mesmo essa carbonização permanecendo $34 \mathrm{~h}$ nas duas primeiras fases de carbonização (temperatura de 100 a $\left.275^{\circ} \mathrm{C}\right), 19 \mathrm{~h}$ na terceira fase e $17 \mathrm{~h}$ na última fase, as temperaturas foram superiores às verificadas 
na primeira carbonização, conforme verificado na Figura 2A. Após $56 \mathrm{~h}$ da ignição do forno, a temperatura máxima igual a $476^{\circ} \mathrm{C}$ foi alcançada para a segunda carbonização.

Para alcançar as metas de tempo e temperatura estabelecidas na Tabela 1 , durante a terceira carbonização os seis controladores de ar foram deixados com abertura maior do que aquelas das carbonizações anteriores. Assim, a fase de secagem da madeira, quando a temperatura não deveria ultrapassar $150^{\circ} \mathrm{C}$, teve duração média de $15 \mathrm{~h}$, enquanto a segunda fase de carbonização, quando a temperatura varia entre 150 e $275^{\circ} \mathrm{C}$, teve duração média de 11 h. Observa-se, na Figura 2A, que nessa carbonização o forno permaneceu menos tempo na fase endotérmica, cerca de um terço do tempo total, em comparação com as carbonizações anteriores, que permaneceram por $35 \mathrm{~h}$, ou metade do tempo total.

Em relação às fases exotérmicas, verificou-se que a terceira fase, quando a temperatura apresenta variação entre 275 e $400^{\circ} \mathrm{C}$, foi mantida por $23 \mathrm{~h}$. A fase de fixação do carbono no carvão vegetal (quarta fase) ocorreu durante $22 \mathrm{~h}$, sendo a temperatura máxima dessa carbonização $\left(486^{\circ} \mathrm{C}\right)$ alcançada após 56 h do início da carbonização.

Para a quarta carbonização, considerando a temperatura da cúpula, a fase de secagem da madeira, quando a temperatura deve permanecer entre $100 \mathrm{e}$ $150{ }^{\circ} \mathrm{C}$, teve duração de $15 \mathrm{~h}$, enquanto para a segunda fase, variação da temperatura entre 150 e $275^{\circ} \mathrm{C}$, o tempo de exposição foi de $11 \mathrm{~h}$. A terceira fase ocorreu durante $24 \mathrm{~h}$ e a última, com temperatura variando de 400 a $470{ }^{\circ} \mathrm{C}$, aconteceu da $51^{\text {a }}$ hora de carbonização até o fim do processo $(19 \mathrm{~h})$, quando a temperatura do forno decresceu de maneira natural. A temperatura máxima igual a $455^{\circ} \mathrm{C}$ foi alcançada na cúpula do forno após $60 \mathrm{~h}$ do início da carbonização.

De acordo com a Figura 2B, durante a primeira carbonização a temperatura média da parte inferior do forno permaneceu abaixo de $100^{\circ} \mathrm{C}$ até a $50^{\mathrm{a}}$ hora de carbonização, e somente após 57 h de carbonização é que a temperatura ultrapassou os $200^{\circ} \mathrm{C}$, alcançando a temperatura máxima igual a $403^{\circ} \mathrm{C}$ após 64 h do início do processo. De acordo com a Figura 2B, essa carbonização apresentou temperaturas inferiores às demais carbonizações realizadas neste estudo.
Para a segunda carbonização, observou-se que na parede do forno a temperatura média de $100^{\circ} \mathrm{C}$ foi alcançada a partir da $40^{\mathrm{a}}$ hora. Portanto, para essa carbonização a parte inferior do forno permaneceu menos tempo a temperaturas inferiores a $100^{\circ} \mathrm{C}$, em comparação com a primeira carbonização. Temperaturas superiores a $300{ }^{\circ} \mathrm{C}$ na parte inferior do forno foram alcançadas a partir da $55^{\mathrm{a}}$ hora, com a temperatura máxima de $447^{\circ} \mathrm{C}$ ocorrendo na $66^{\mathrm{a}}$ hora.

A parte inferior do forno a partir da $38^{\mathrm{a}}$ hora da terceira carbonização atingiu temperaturas acima de $100^{\circ} \mathrm{C}$, enquanto temperaturas superiores a $300^{\circ} \mathrm{C}$ foram mantidas da $54^{\text {a }}$ hora até o encerramento da carbonização ( $70^{\mathrm{a}}$ hora), ou seja, manteve-se por $16 \mathrm{~h}$. Para essa carbonização ainda houve diferença significativa de temperatura entre a parte inferior e a parte superior do forno, assim como nas carbonizações anteriores.

Para a quarta carbonização, temperaturas inferiores a $100{ }^{\circ} \mathrm{C}$ na parte inferior do forno permaneceram até a $31^{\text {a }}$ hora de carbonização. A partir da $54^{\text {a }}$ hora, as temperaturas medidas na parede do forno foram superiores a $300^{\circ} \mathrm{C}$, permanecendo até a $70^{\mathrm{a}}$ hora, quando a carbonização foi encerrada. Devido ao maior incremento da temperatura na parede do forno (Figura 2B), a quarta carbonização apresentou a menor geração de atiço $(3,28 \%)$, em relação às demais carbonizações, conforme verificado na Tabela 3 .

\subsection{Funcionamento da fornalha}

Para o melhor desempenho do sistema fornofornalha, verificou-se que o acendimento da fornalha deveria ocorrer simultaneamente à ignição do forno. Para isso, a fornalha foi abastecida com resíduos, como atiço gerado em carbonizações anteriores, além de resíduos lignocelulósicos gerados durante a colheita das árvores. O mesmo procedimento foi realizado por Cardoso et al. (2011), que relataram que o objetivo seria aquecer a fornalha e criar um gradiente de temperatura entre ela e o forno, fazendo que ocorresse tiragem mais eficiente dos gases do forno para a fornalha.

Segundo Taccini (2011), do início da carbonização até o forno atingir temperatura média de $280^{\circ} \mathrm{C}$ na cúpula do forno, o que corresponde às fases I e II da carbonização, o processo é endotérmico, ocorrendo liberação de vapor de água e $\mathrm{CO}_{2}$. Portanto, até a $28^{\mathrm{a}}$ hora de carbonização foi necessária a queima de grande quantidade de resíduos 
lignocelulósicos dentro da fornalha, totalizando $72,7 \%$ do total de resíduos consumidos para fornecimento de energia para combustão dos gases de baixo poder calorífico e alta umidade. Tal procedimento foi imprescindível para evitar a liberação de grande volume de gases, principalmente vapor de água, para o ambiente, diminuindo, assim, a poluição visual durante a produção de carvão vegetal.

Durante a terceira fase de carbonização, quando a temperatura média da cúpula do forno atingiu $375^{\circ} \mathrm{C}$ e a temperatura média da parede do forno alcançou temperatura de $170{ }^{\circ} \mathrm{C}$, verificou-se que os gases de saída do forno estavam na temperatura de $160^{\circ} \mathrm{C}$. Segundo Taccini (2011), nessas condições ocorre a emissão mínima de vapor de água e elevam-se as concentrações de $\mathrm{CO}$ e $\mathrm{CH}_{4}$. Portanto, o abastecimento da fornalha com resíduos foi suspenso, pois os gases gerados nessa fase são inflamáveis e de elevado poder calorífico, passando a exercer a função de combustível para a combustão no interior da fornalha.

A queima dos gases na fornalha ocorreu durante $36 \mathrm{~h}$, tendo sido necessário abastecer a fornalha durante as primeiras horas até que o volume de gases com alto poder calorífico fosse suficiente para a manutenção da chama, por isso o consumo de $100 \mathrm{~kg}$ de resíduos durante a terceira fase de carbonização $(9,1 \%$ do total de resíduos). A queima de gases combustos da carbonização ocorreu durante $24 \mathrm{~h}$, sem a necessidade de abastecimento, ou seja, durante $34 \%$ do tempo total de carbonização.

Durante a queima dos gases no interior da fornalha foram obtidas temperaturas variando de 650 a $1.150{ }^{\circ} \mathrm{C}$, sendo essa faixa de temperatura suficiente para a combustão completa do alcatrão, do licor pirolenhoso, dos fenóis

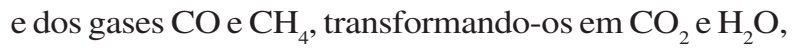
conforme atestado por Cardoso et al. (2010).

Verificou-se, ao final da carbonização, fase IV, que o volume de gases foi reduzido, sendo necessários novos abastecimentos com resíduos para manutenção da chama e combustão dos gases. A partir da $60^{\mathrm{a}}$ hora de carbonização, em intervalos de $4 \mathrm{~h}$, a fornalha foi abastecida com maior volume de resíduos para criar um gradiente de temperatura e pressão entre a fornalha e o forno, para realizar a tiragem final dos gases de dentro do forno até cessar a carbonização, resultando no gasto de $200 \mathrm{~kg}$ de resíduo, 18,2\% do total.

Revista Árvore, Viçosa-MG, v.37, n.3, p.557-566, 2013
Quando se encerrou a carbonização, a chama no interior da fornalha estava enfraquecida, sendo necessários somente o fechamento e vedação da entrada primária de ar para finalização da combustão na fornalha.

A queima de resíduos para manter o funcionamento da fornalha, principalmente durante a fase endotérmica da carbonização, não será necessária quando o sistema estiver funcionando em sincronização com o maior número de fornos.

\subsection{Rendimentos gravimétricos das carbonizações}

O rendimento em carvão vegetal da primeira carbonização (Ajuste) realizada no sistema forno-fornalha foi de $26,40 \%$, valor considerado baixo, uma vez que o esperado seria no mínimo $30 \%$, sendo, então, elevado o porcentual de atiço gerado, 21,60\%. Esse fato foi ocasionado pelo elevado tempo de exposição da madeira ( $50 \%$ do tempo de carbonização) em temperaturas inferiores a $300^{\circ} \mathrm{C}$, não ocorrendo a conversão da madeira em carvão vegetal. As peças de madeira semicarbonizadas (atiço) tiveram, nessa carbonização, tamanho variável de 30 a $45 \mathrm{~cm}$, localizando-se na parte central do forno e próximo à porta. $O$ porcentual de finos nessa carbonização foi inferior a 5\%, provavelmente devido ao controle adequado da temperatura, realizado por meio da utilização de medidor de infravermelho, não sendo verificadas temperaturas superiores a $480{ }^{\circ} \mathrm{C}$ durante a carbonização. Na segunda carbonização, obteve-se rendimento gravimétrico em carvão vegetal de $32,15 \%$, com menor produção de atiço $(12,42 \%)$, sendo estes gerados na parte central do forno e com tamanho variando de 20 a $30 \mathrm{~cm}$. A maior porcentagem de carvão vegetal foi devida à abertura de dois novos controladores de ar próximo à porta e manutenção do forno em temperaturas mais próximas ao limite superior definido para cada faixa teórica.

$\mathrm{Na}$ terceira carbonização, o rendimento gravimétrico em carvão vegetal foi igual a 31,80\%, valor próximo ao alcançado na segunda carbonização, porém com pequena redução na porcentagem de atiço $(10,83 \%)$. Apesar da redução do porcentual de atiço nessa carbonização, ele ainda foi considerado elevado, ou seja, insatisfatório para o sistema, pois como o controle foi baseado em faixas ideais de carbonização e o controle da temperatura do forno, efetuado por meio de sensor infravermelho esperava-se um valor inferior a $5 \%$. 
Visando reduzir o porcentual de atiço e elevar o porcentual de carvão vegetal, na quarta carbonização, além do cumprimento das faixas de carbonização, aumentou-se o tempo de abertura dos controladores de ar após a chegada da frente de carbonização. Os controladores próximos à porta ficaram abertos durante $10 \mathrm{~h}$, os controladores centrais durante $11 \mathrm{~h}$ e os mais próximos à saída de gases por $9 \mathrm{~h}$. Essas modificações promoveram o aumento do rendimento gravimétrico em carvão vegetal para 35,61\% e a redução do porcentual de atiço para 3,28\%. O comprimento máximo dos atiços gerados nessa carbonização foi de $10 \mathrm{~cm}$, localizando-se principalmente na parte central do forno.

Nas carbonizações 2, 3 e 4, cujo controle foi realizado com base nas faixas de tempo e temperatura apresentadas na Tabela 1, verificou-se que o sistema forno-fornalha proporcionou rendimento gravimétrico médio em carvão vegetal de $33 \%$, considerado satisfatório, pois os atuais fornos de carvão vegetal têm rendimento médio de 28 a $30 \%$. Em fornos de alvenaria do tipo "rabo-quente", os mais utilizados por pequenos produtores, o rendimento gravimétrico em carvão vegetal geralmente alcança o máximo de 25\%, e, segundo Minette et al. (2007), nesse tipo de forno o trabalhador fica exposto a altas temperaturas e aos gases originários da carbonização da madeira.

Cardoso et al. (2010) obtiveram rendimento médio de $29 \%$ de carvão vegetal e $4 \%$ de atiço em carbonizações realizadas em um forno retangular com dimensões reduzidas, denominado MF1-UFV, com capacidade para 8 st. Já Arruda et al. (2011) obtiveram 28,5\% de rendimento em carvão vegetal de madeira com $48 \%$ de umidade, para carbonizações realizadas em fornos retangulares com capacidade para $160 \mathrm{st}$.

O valor médio de $8,85 \%$ de atiço no sistema fornofornalha foi considerado elevado, pois pode ser reduzido, o que reflete no aumento do rendimento gravimétrico em carvão vegetal, como foi verificado na quarta carbonização desta pesquisa. Para tal, devem-se manter os controladores de ar por mais tempo abertos após a chegada da frente de carbonização e cumprir os tempos e temperaturas estabelecidos, buscando controlar a temperatura média próxima ao limite superior.

\section{CONCLUSÃO}

O sistema forno-fornalha apresentou produção satisfatória de carvão vegetal, com baixa produção de atiços através do controle da carbonização realizado com base nas faixas de carbonização em função do tempo e da temperatura, permitindo o reconhecimento das fases do processo e auxiliando-o na tomada de decisão sobre as ações a serem executadas no forno.

A determinação do perfil térmico de cada carbonização permite o reconhecimento de falhas durante o controle da carbonização e do resfriamento, sendo utilizado como ferramenta para correção nas carbonizações posteriores, além de apresentar a evolução da temperatura no interior do forno ao longo do tempo, o que pode explicar possíveis resultados.

A fornalha funcionou adequadamente, realizando a combustão dos gases gerados na carbonização durante um terço do tempo total de carbonização e sem a necessidade de abastecimento com resíduos lignocelulósicos, além de reduzir quase que a totalidade das emissões de fumaça para o ambiente.

\section{AGRADECIMENTOS}

Ao Conselho Nacional de Desenvolvimento Científico e Tecnológico (CNPq), à Fundação de Amparo à Pesquisa do Estado de Minas Gerais (FAPEMIG), à Secretaria de Estado e Ciência, Tecnologia e Ensino Superior (SECTES), ao Polo de Excelência em Florestas e à Associação das Siderúrgicas para Fomento Florestal (ASIFLOR).

\section{REFERÊNCIAS}

ARRUDA, T. P. M. et al. Avaliação de duas rotinas de carbonização em fornos retangulares. Revista Árvore, v.35, n.4, p.949-955, 2011.

\section{ASSOCIAÇÃO BRASILEIRA DE PRODUTORES} DE FLORESTAS PLANTADAS-ABRAF. 2012. Anuário estatístico da ABRAF: ano base 2011. Brasília: 2012. 145p.

CARDOSO, M. T. et al. Construção de um sistema de queima de gases da carbonização para redução da emissão de poluentes. Cerne, v.16, Suplemento, p.115-124, 2010.

CARVALHO, S. R. et al. Instrumentação térmica aplicada ao processo de produção de carvão vegetal em fornos de alvenaria. Revista Árvore, v.36, n.4, p.787-796, 2012. 
FREDERICO, P. G. U. Influência da densidade e composição química da madeira sobre a qualidade do carvão de Eucalyptusgrandis W. Hill ex Maiden e de híbridos de Eucalyptus grandis $\mathbf{x}$ Eucalyptus urophylla S.T. Blake. 2009. 75 f. Dissertação (Mestrado em Ciência Florestal) Universidade Federal de Viçosa, Viçosa, MG, 2009.

MINETTE, L. J. et al.Avaliação da carga de trabalho físico e análise biomecânica de trabalhadores da carbonização em fornos tipo "rabo-quente".

Revista Árvore, v.31, n.5, p.853-858, 2007.

OLIVEIRA, A. C. et al. Parâmetros de qualidade da madeira e do carvão vegetal de Eucalyptus pellita F. Muell. Scientia Forestalis, v.38, n.87, p.431-439, 2010.

PEREIRA, B. L. C. Qualidade da madeira de Eucalyptus para a produção de carvão vegetal. 2012. 102f. Dissertação (MestradoCiência Florestal) - Universidade Federal de Viçosa, Viçosa-MG, 2012.

RAAD, T. J.; PINHEIRO, P. C. C.; YOSHIDA, M. I. Equação geral de mecanismos cinéticos da carbonização do Eucalyptus spp. Cerne, v.12, n.2, p.93-106, 2006.
REZEnde, J. B.; SAntos, A. C. A cadeia produtiva do carvão vegetal em Minas Gerais: pontos críticos e potencialidades.Viçosa, MG: U.R. EPAMIG ZM, 2010. 80p.

SANTOS, R. C. et al.Análise termogravimétrica em clones de eucalipto como subsídio para a produção de carvão vegetal. Cerne, v.18, n.1, p.143-151, 2012.

SJÖSTRÖM, E. Wood chemistry fundamentals and applications.2.ed. London: Academic Press, 1993.293p.

TACCINI, M. M. Estudo das metodologias da Convenção-Quadro das Nações Unidas sobre Mudanças Climáticas, referentes à avaliação de emissões de gases de efeito estufa na produção de carvão vegetal. 2011. 86 f. Dissertação (Mestrado em Ciência e Tecnologia de Produtos Florestais) - Universidade de São Paulo, Piracicaba, 2011.

YANG, H. et al.Characteristics of hemicellulose, cellulose and lignin pyrolysis. Fuel, v.86, p.17811788, 2007. 